\title{
Educação Estatística No Contexto Da Formação De Professores Dos Anos Iniciais Do Ensino Fundamental: Mobilização Dos Saberes De Conteúdo Estatístico
}

\author{
Statistical Education In Context Of Teacher Education In The Early Years In Context \\ Of Elementary Education: Mobilization Of Statistical Knowledge Content
}

\author{
Elvys Wagner Ferreira da Silva* \\ Secretaria Municipal de Educação- SEMED-São Luís \\ Faculdade Gianna Beretta - São Luís \\ Elizabeth Gomes Souza** \\ Universidade Federal do Pará
}

\begin{abstract}
Resumo
Este estudo investiga a formação dos futuros dos professores dos anos iniciais no que tange aos Saberes Docentes atinentes aos conteúdos estatísticos. Ancorada nos estudos de Shulman (1986), Tardif (2002) e Gauthier et. al. (1998) acerca dos Saberes Docentes coadunando com os referenciais teóricos relacionados à Educação Estatística a pesquisa investigou os saberes relacionados aos conteúdos matemáticos mobilizados na formação docente de professores dos anos iniciais do Ensino Fundamental acerca dos Saberes de Conteúdo Estatístico. O estudo foi desenvolvido com a participação de alunos do curso de Licenciatura Integrada em Educação em Ciências, Matemática e Linguagens/UFPA. O cenário do trabalho de campo se deu em dois contextos, a sala de aula do curso de formação inicial e a sala de aula dos anos iniciais. A composição analítica foi constituída por transcrições de áudios e vídeos referente as atividades desenvolvidas pelos licenciandos. Os Saberes Estatísticos mobilizados nos campos de pesquisa foram pautados na prática profissional de futuros professores relacionados à construção, leitura, interpretação de gráficos.
\end{abstract}

Palavras-chaves: Saberes Docentes, Educação Estatística, Saberes Estatísticos.

\begin{abstract}
This study investigates the formation of the teachers' future in the early years of teaching in relation to the Teaching Knowledge related to the statistical content. Anchored in the studies of Shulman (1986), Tardif (2002), Gauthier et. al. (1998) on Teaching Knowledge in accordance with the theoretical references related to Statistical Education, the research investigated the knowledge related to the statistical content mobilized in the teacher education in the early years of Elementary School Education

\footnotetext{
* Mestre em Educação em Ciências e Matemática- Universidade Federal do Pará (UFPA). Professor efetivo da Rede Municipal de Educação de São Luís. Professor da Faculdade Gianna Beretta, São Luís, Maranhão, Brasil. elvys.wagner@gmail.com

Doutora em Ensino, Filosofia e História das Ciências- Universidade Estadual de Feira de Santana (UEFS) e Universidade Federal da Bahia(UFBA). Professora Adjunta da Faculdade de Educação Matemática e Científica e Programa de Pós-graduação em Educação em Ciências e Matemáticas- Universidade Federal do Pará (UFPA), Belém, Pará, Brasil. elizabethgs@ufpa.br
}

REVEMAT, Florianópolis (SC), v.14, Edição Especial Educação Estatística, p.1-21, 2019. 
on the Knowledge of Statistical Content. The study was developed with the participation of students of the course of Integrated Degree in Education in Sciences, Mathematics and Languages / UFPA. The work field scenario took place in two contexts, the classroom of the initial training course and the classroom of the early years. The analytical composition consisted of transcriptions of audios and videos related to the activities developed by the graduates. The Statistical Knowledge mobilized in the research fields was anchored in the teachers' professional practice related to construction, reading, and interpretation of graphs.

Keywords: Teachers' Knowledge, Statistical Education, Statistical Knowledge.

\section{Introdução}

O grande fluxo de informações estatísticas apresentadas em tabelas e gráficos presentes no cotidiano das pessoas são cada vez mais frequentes. Na esfera escolar, os alunos ao se depararem com os conceitos estatísticos precisam saber interpretar esses dados de modo que compreendam o significado dessas informações.

À luz desse contexto, os Parâmetros Curriculares Nacionais (Brasil, 1997; 1998) e a Base Nacional Comum Curricular (Bncc, 2017) coadunam no sentido de que os conceitos estatísticos tornam-se mais significativos quando relacionados à problemas da vida cotidiana. Nesse sentido, entendendo sua relevância na sociedade, as informações estatísticas precisam ser acessíveis às crianças, aos jovens, aos adultos, primordialmente na formação de professores, desse modo, a presente pesquisa adentra no universo da formação de professores dos anos iniciais com o intuito de evidenciar a mobilização dos conteúdos relacionados à Estatística dentro de uma perspectiva formativa vinculada à prática profissional docente.

À luz dessas considerações, a presente pesquisa no contexto da formação de professores dialoga com dois campos distintos: os Saberes Docentes e a Educação Estatística. Com a comunhão desses campos de estudo, foi possível propor reflexões acerca dos saberes docentes à luz das concepções de Shulman (1986), Tardif (2002), Gauthier et. al. (1998), com a finalidade de discutir implicações para a formação inicial de professores dos anos iniciais. Também, trazemos para discussão, literaturas voltadas à Educação Estatística com os estudos de Lopes (1998; 2003; 2010), Cazorla (2002; 2004) e Batanero e Diaz (2010).

Os futuros professores, cujos saberes foram analisados neste estudo, compreendem o público de estudantes matriculados no $4^{\mathrm{o}}$ período do curso de Licenciatura Integrada em Educação em Ciências, Matemática e Linguagens ofertado pelo Instituto de Educação 
Matemática e Científica/UFPA ${ }^{1}$. Em relação ao cenário do trabalho de campo a investigação se deu em dois contextos: o campo da formação e o campo da prática pedagógica.

O campo da formação compreende a formação desenvolvida dentro do espaço acadêmico, enquanto que o campo da prática pedagógica se atém a sala de aula dos espaços escolares. No campo da formação as atividades foram planejadas para serem desenvolvidas com alunos dos $1^{\circ}, 2^{\circ}$ e $3^{\circ}$ anos (alunos com 6 a 8 anos de idade) e no campo da prática pedagógica as atividades desenvolvidas foram com alunos do $3^{\circ}$ ano.

O desenho metodológico da pesquisa se deu no campo da formação com atividades referentes aos conhecimentos específicos e pedagógicos da Estatística planejadas pelo pesquisador e no campo da prática pedagógica a dinâmica foram atividades pedagógicas tendo os licenciados como protagonistas em aulas de escolas da rede pública e particular de ensino. Os instrumentos de coletas de dados para a composição analítica se deram através de transcrições de áudios e vídeos referente as atividades desenvolvidas pelos licenciandos.

Neste artigo, foram analisados os Saberes de Conteúdo Estatístico a qual chamamos de Saberes Estatísticos. Em particular estudaremos os saberes sobre construção de gráficos e leitura e interpretação dos dados engendrados, mobilizados no campo da formação de professores para o campo da prática pedagógica evidenciados nas atividades pedagógicas relativas à Estatística.

\section{Estatística No Tocante A Formação Inicial De Professores Dos Anos Iniciais}

Nos mais diversos campos do conhecimento, como Ciências Exatas, Sociais, Humanas e Saúde entre outros, os conhecimentos referentes à Estatística são fundamentais para a formação acadêmica e, sobretudo, para o exercício profissional futuro. No tocante, a formação inicial de professores há necessidade que os conceitos relativos à Estatística sejam trabalhados desde os anos iniciais de escolaridade (Lopes, 2003).

Em relação aos cursos de Formação de Professores dos Anos Iniciais, em sua maioria deles, existe poucas disciplinas de Estatística em sua grade curricular. O que há são disciplinas relacionadas à Matemática para os anos iniciais do Ensino Fundamental que abordam os conceitos estatísticos (Cazorla, 2015). E quando a formação estatística é realizada, o mesmo

\footnotetext{
${ }^{1}$ Trata-se de um curso oferecido na instituição a partir de 2010, cujo o foco curricular reside em consolidar uma formação pautada em práticas de ensino de natureza interdisciplinar. Os egressos serão habilitados para atuar em sala de aula nos primeiros anos do ensino fundamental.
} 
ocorre dentro de uma perspectiva a concentrar-se em aspectos procedimentais do cálculo (Souza, 2014).

Para explicitar essa situação, pesquisas apontam que no Brasil os cursos de Pedagogia não apresentam disciplinas que contemplam os conteúdos de Estatística como foi notadamente constatada nos estudos de Cazorla (2015). Na pesquisa da autora:

Duas disciplinas aparecem ligadas a estes cursos: Estatística Educacional (indicadores educacionais) e Estatística Aplicada à Educação, enquanto ferramenta de tratamento de dados e noções de inferência estatística. [...] nenhuma dessas disciplinas contempla a Didática da Estatística, o que também não fica explicito na disciplina de Metodologia de Ensino da Matemática. Observa-se, ainda, que os alunos dos cursos de Pedagogia mostram resistência à Matemática e Estatística, [...] (Cazorla, 2015, p. 1).

A pesquisa corrobora que as poucas disciplinas existentes, ainda são desconexas com as questões didático-pedagógicas colaborando ainda para o distanciamento dos alunos à Matemática. É evidente que muitos professores dos anos iniciais têm dificuldade em ensinar Matemática devido à ausência desses conteúdos, sobretudo, de Estatística durante seu processo formativo relativo à didática da Estatística (Batanero \& Diaz, 2010; Kataoka et. al, 2011; Martins \& Carvalho, 2018).

À luz desse contexto, os cursos de formação docente voltados para os anos iniciais devem proporcionar formação didática relacionada à Estatística para que os professores dos anos iniciais sintam-se devidamente preparados para poder ensinar tais conteúdos, porque não se pode ensinar aquilo que não se sabe ou aquilo que se tem dúvidas (Batanero \& Diaz, 2010; Kataoka et. al. 2011), pois no processo formativo o professor precisa exercer efetivamente o papel de mediador na construção do conhecimento. Desta forma, é importante desmistificar a crença que os conceitos estatísticos são de difícil compreensão tanto para professores, futuros professores, bem como para alunos de qualquer nível escolar.

Em virtude dessas colocações, Guimarães (2009) e Lopes (2010) destaca em sua pesquisa que os professores dos anos iniciais advindos dos cursos de Pedagogia se sentem despreparados para desenvolver os conteúdos relativos à Estatística. Os professores afirmam que não possuem conhecimentos suficientes sobre estratégias metodológicas para desenvolver os conteúdos, ficando ainda restritos às atividades propostas pelos livros didáticos.

Para Manfredo, Gonçalves \& Levy (2011) os currículos dos cursos, as práticas docentes, os saberes, concepções e crenças precisam ser avaliados e questionados visando à formação dos docentes que ensinam nos anos iniciais do Ensino Fundamental. Destacam que a formação estatística adquirida na formação inicial não repercute na prática pedagógica dos professores no que diz respeito aos conhecimentos específicos, pedagógicos e metodológicos diante do 
novo comportamento social e das novas demandas da sociedade da informação e do conhecimento.

O Ensino de Estatística apresenta problemas na formação do professor de Matemática e na formação matemática dos professores dos anos iniciais. No campo da formação dos professores dos anos iniciais a abordagem da Estatística se dá, em uma disciplina específica de Matemática para os anos iniciais determinada pelos cursos. Assim, na ausência de disciplinas relacionadas à Estatística, cabe ao Ensino de Matemática nesse processo, a responsabilidade de não só ensinar o domínio dos números, bem como a organização de dados e leitura de gráficos (Lopes, 1998). De fato, é o que normalmente ocorre em muitos cursos de formação docente, a atenção é dada ou direcionada aos aportes teóricos da Estatística Descritiva atrelados aos cálculos, deixando de investir nas análises e discussões que a Estatística Inferencial propõe a partir dos dados coletados e organizados em gráficos e tabelas.

Assim, há um consenso entre os pesquisadores da necessidade da formação dos professores sobre essa temática, de modo que sejam capazes de desenvolverem Estatística com os alunos, preparando-os para que se tornem cidadãos estatisticamente alfabetizados (Batanero \& Diaz, 2010). Para isso a Educação Estatística precisa atingir os espaços de formação inicial de professores dos anos iniciais, e, por conseguinte, subsidiar a formação continuada e futuramente o trabalho docente visando atingir o processo de ensino e aprendizagem acerca das questões pertinentes à Estatística na Educação Básica.

\section{Saberes Docentes Na Formação De Professores À Luz De Shulman (1986), Tardif (2002) E Gauthier Et. Al. (1998)}

Neste seção, temos a finalidade de discutir as implicações das pesquisas sobre os saberes da docência para a formação inicial de professores dos anos iniciais, analisando algumas obras de referência como Shulman (1986), Tardif (2002), Gauthier et. al. (1998), e produções de outros estudiosos que têm como foco de discussão os saberes docentes.

Apresentamos algumas concepções sobre os saberes da docência na perspectiva desses teóricos e apontar os saberes relacionados aos conhecimentos necessários para o trabalho docente nos anos iniciais no âmbito da formação inicial de professores no contexto do campo da formação e do campo da prática pedagógica.

Iniciaremos com as contribuições de Shulman (1986) evidenciando a base de conhecimentos para o ensino (knowledge base) que se refere ao conjunto de conhecimentos, 
compreensões, habilidades e disposições indispensáveis à atuação docente em diversas situações de ensino, com o propósito de atingir os objetivos relacionados à aprendizagem e à formação dos alunos, bem como por diversas experiências do professor, ao longo da sua trajetória pessoal, acadêmica e profissional

O autor apresenta três categorias de conhecimentos: o conhecimento do conteúdo específico, o conhecimento pedagógico do conteúdo e o curricular. Argumenta que esses conhecimentos são construídos na prática do professor, no confronto com os desafios da prática docente cotidiana, seja na formação inicial, seja no exercício da atividade docente.

Para o autor o conhecimento do conteúdo específico refere-se aos conteúdos específicos da disciplina que o professor leciona, ou seja, conteúdos da área que o professor é especialista (Gonçalves \& Gonçalves, 1998). O conhecimento pedagógico do conteúdo, para Shulman (1986) é um tipo de conhecimento que sobressai o conhecimento do conteúdo específico, é uma combinação entre o conhecimento da matéria e o conhecimento de como ensinar, incluem-se todas as formas possíveis de expor o conteúdo para torná-lo compreensível aos alunos, como esquemas, exemplos, explicações, contraexemplos. Enquanto que o conhecimento curricular, que Shulman (1986), consiste no conjunto de programas constituídos para o ensino de assuntos e tópicos específicos em um certo nível, bem como a variedade de materiais instrucionais disponíveis àqueles programas.

Gauthier et. al. (1998) é outro autor que analisa os saberes docentes e suas implicações na formação de professores atrelados à pratica pedagógica. Os autores defendem a existência de um repertório de conhecimentos dos professores, construídos no trabalho docente.

Para Gauthier et. al. (1998), o saber disciplinar representa aquele saber produzido pelos pesquisadores e cientistas nas diversas áreas do conhecimento, conceitos e métodos relativos a uma disciplina. O saber curricular é o saber que a escola enquanto instituição seleciona e organiza para ser ensinado nos programas e currículos escolares. Outro saber evidenciado pelo autor é o saber das ciências da educação que está relacionado aos saberes que todo professor adquire durante o período de formação, conhecimentos profissionais a respeito do seu ofício e da educação de um modo geral.

Temos ainda, o saber da tradição pedagógica se refere ao saber de dar aulas e estão relacionados à concepção prévia que os futuros professores no início da formação docente tem a respeito do magistério. Esses saberes serão adaptados e modificados pelo saber experiencial, e legitimados ou não pelo saber da ação pedagógica, ou seja, pela prática pedagógica. O saber experiencial que diz respeito ao saber pertinente às experiências de cada professor, realizadas rotineiramente em sala de aula ao longo da sua carreira, em contrapartida, não legitimados por 
meio de métodos científicos. Por fim, o saber da ação pedagógica é o saber experiencial dos professores a partir do momento que é legitimado através das pesquisas realizadas em sala de aula. Com efeito, essas pesquisas quando socializadas proporcionam contribuir significativamente para o aperfeiçoamento da prática pedagógica dos professores.

Tardif (2002) também tem seus estudos ligados à questão da pluralidade do saber docente e juntamente com Gauthier et. al. (1998) defendem o estudo da natureza desses saberes como fundamento de uma epistemologia da prática dos professores. $\mathrm{O}$ autor destaca a existência de quatro tipos de saberes que alicerçam o trabalho e a formação dos professores.

Destacamos primeiramente, os saberes da formação profissional como o conjunto de saberes transmitidos pelos cursos de formação de professores. Os saberes pedagógicos relacionados à prática do professor no que diz respeito às técnicas e métodos de ensino se transformam em saberes legitimados na formação científica através da formação inicial ou continuada. Já os disciplinares são reconhecidos e identificados nos diversos campos do conhecimento e que se encontram integrados às universidades na forma de disciplinas e incorporados à prática pedagógica mobilizados nos cursos de formação inicial e continuada.

Os saberes curriculares são saberes socialmente produzidos pelos professores ao longo da atuação profissional e relacionados às instituições educacionais devendo ser transmitidos aos estudantes através dos saberes disciplinares. Os saberes experienciais são saberes mobilizados pelos professores no exercício de suas atividades profissionais docentes desenvolvendo saberes específicos baseados em seu trabalho cotidiano.

\section{Saberes De Conteúdo Estatístico: Saberes Estatísticos}

O desenvolvimento das atividades relativas à temática de Estatística se deu em dois contextos: a sala de aula dentro do curso de formação inicial na universidade e a sala de aula dos anos iniciais do Ensino Fundamental dentro de escolas da rede pública e particular de ensino. As atividades foram realizadas no campo da formação (a sala de aula do curso de formação inicial), abordando o conteúdo estatístico por meio de aulas expositivas constituídas de atividades em grupo, socialização de atividades pedagógicas e discussões coletivas e para o campo da prática pedagógica (a sala de aula dos anos iniciais do Ensino Fundamental) e particular) as atividades docentes foram desenvolvidas, exclusivamente, pelos licenciandos.

Em virtude dos dois contextos formativos, contemplamos na composição analítica dos dados a inserção de fragmentos de episódios que demonstram a mobilização dos saberes no campo da formação e no campo da prática pedagógica. Com essa proposta de análise 
destacamos em alguns momentos a comunhão dos saberes ora manifestados no campo da formação, ora no campo da prática pedagógica, destacamos ainda, saberes que foram mobilizados em apenas um dos campos.

A identificação das atividades no campo da formação $(C F)$ e no campo da prática pedagógica (CP) foi a seguinte: Atividade 01 ( $\mathrm{CF}-1^{\circ}$ ano); Atividade 02 ( $\mathrm{CF}-2^{\circ}$ ano); Atividade 03 ( $\mathrm{CF}-3^{\circ}$ ano); Atividade 01 ( $\mathrm{CP}-3^{\circ}$ ano) e Atividade 02 ( $\mathrm{CP}-3^{\circ}$ ano). A fala dos licenciandos expressos nos desdobramentos das atividades foram identificados como L01, L02, L03 e assim sucessivamente, pesquisador (PE) e a professora (PR).

\subsection{O Que São Os Saberes Estatísticos?}

Os Saberes Estatísticos dizem respeito aos conteúdos estatísticos que inicialmente foram estudados durante os encontros formativos, e em seguida, compuseram a prática pedagógica dos futuros professores em atividades ministradas nas escolas. São saberes que não são produzidos pelos professores, mas, socialmente produzidos por pesquisadores e cientistas ligados à educação e ensinados aos alunos.

Propomos num primeiro momento no campo da formação uma abordagem dos conceitos básicos da Estatística, apresentando sua definição, utilização e funcionalidade desse estudo tanto no contexto social, quanto no contexto escolar, bem como os tipos de gráficos colunas, barras, setores, linhas e pictogramas -, construção, leitura e interpretação de gráficos e tabelas, além de apresentar sugestões de atividades didáticas, pedagógicas e conceituais voltadas aos anos iniciais.

Os saberes engendrados neste artigo apresentam duas categorias de saberes que emergiram das análises que expressam o processo formativo dos licenciandos que se dá no campo da formação e no campo da prática pedagógica quanto aos saberes estatísticos. Assim, abordamos nas análises os seguintes saberes: saber relacionado à construção de gráficos e o saber da leitura e interpretação dos dados.

\subsection{Saber Relacionado À Construção De Gráficos}

No âmbito desta pesquisa destacamos o Saber relacionado à construção de gráficos mobilizados nos dois contextos. No contexto do campo da formação foi mobilizada a construção de gráficos em atividades organizadas, num primeiro momento, em lista de exercícios, propostos para os licenciandos resolverem. No campo da prática pedagógica esses saberes foram evidenciados em todas as atividades desenvolvidas pelos licenciandos. 
O Saber relacionado à construção de gráficos para a formação dos licenciandos mobilizou discussões e reflexões no campo de formação. Foram evidenciados esses saberes no campo formativo, sendo que no primeiro dia de formação abordaram os tipos de gráficos e a construção deles (colunas, barras, setores, linhas e pictogramas) (Figura 1).
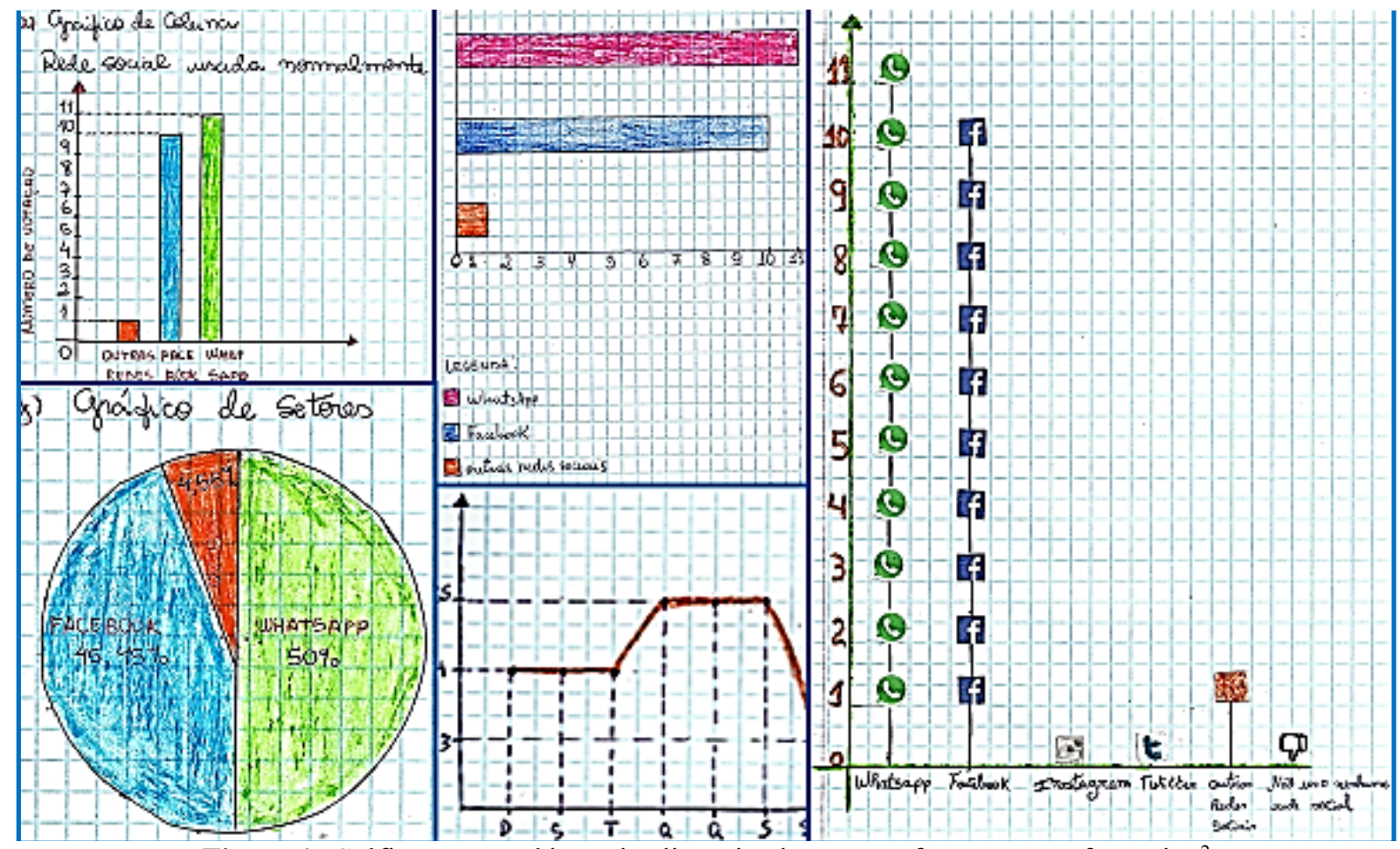

Figura 1: Gráficos construídos pelos licenciandos em tarefas no campo formativo ${ }^{2}$

Fonte: $\mathrm{O}$ autor

Na construção dos gráficos (Figura 1) foi explicado sobre a importância da legenda, da identificação dos eixos, o espaçamento referente à escala utilizada, a proporcionalidade das colunas e barras, do cálculo das porcentagens para os gráficos de setores, das imagens pertinentes à construção de pictogramas, dentre outros aspectos.

A figura 2 apresenta a construção dos gráficos das atividades propostas aos licenciandos dentro de uma perspectiva pedagógica ( $2^{\circ}$ dia de formação) referente ao $1^{\circ}$ ao $3^{\circ}$ ano. $\mathrm{Na}$ Atividade 01 propomos uma pesquisa com o tema fruta preferida (laranja, banana, maçã e uva), na Atividade $02\left(\mathrm{CF}-2^{\circ}\right.$ ano) trata-se de uma pesquisa sobre sobremesa favorita e na Atividade $03\left(\mathrm{CF}-3^{\circ}\right.$ ano) consistiu numa pesquisa que visou descobrir a festa preferida (Círio, Carnaval e Natal). As atividades foram organizadas pelo pesquisador definindo as categorias preestabelecidas, tipo de gráfico que seria confeccionado, inserção e ausência de legendas,

\footnotetext{
${ }^{2}$ A legenda do gráfico de linhas da Figura 1 compreendem as iniciais do dia da semana. Já os demais gráficos, as legendas dizem respeito ao uso de redes sociais, sendo agrupados entre: WhatsApp, Facebook e Outras Redes Sociais.
} 
título do gráfico, confecção dos cartazes com os eixos horizontal e vertical, recursos utilizados (frutas, bonecos, quadradinhos) para a construção das colunas.

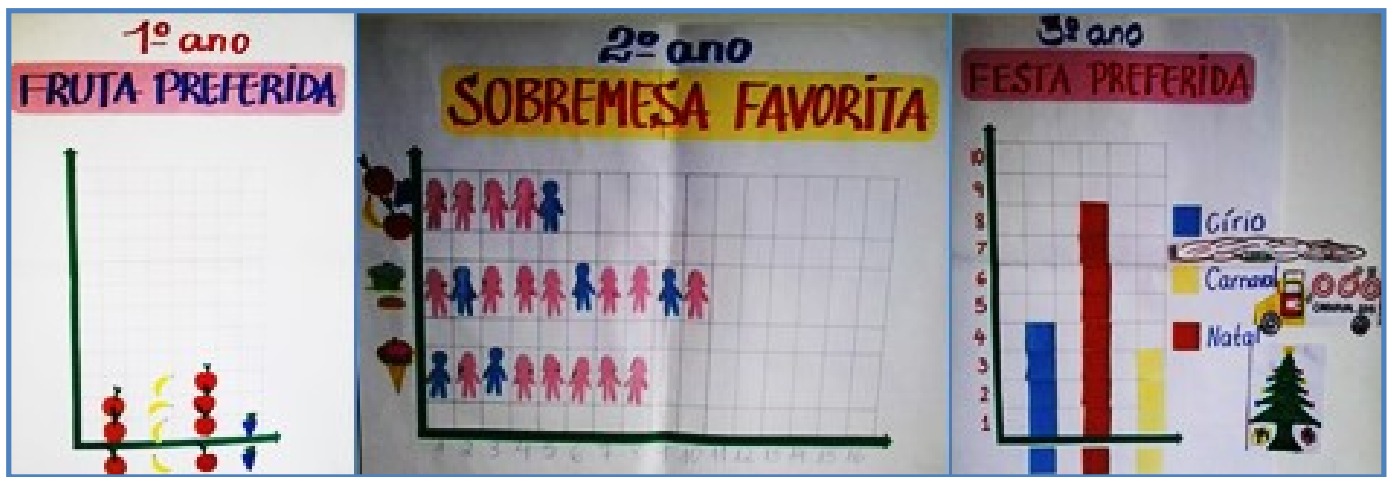

Figura 2: Gráficos construídos com os licenciados nas atividades em cada ano escolar no campo formativo Fonte: $\mathrm{O}$ autor

A condução desse processo de construção se deu nas atividades no campo da formação com a inserção dos próprios licenciandos participando de forma espontânea a votar, escolhendo as variáveis de suas preferências e colando no cartaz. Foram construídos pictogramas de colunas e de barras, além de gráficos de colunas.

A intervenção do pesquisador e da professora durante as socializações das atividades eram recorrentes sempre na intenção de esclarecer, ponderar e pontuar discussões. Na Atividade $01\left(\mathrm{CF}-1^{\circ}\right.$ ano $)$ a professora chama atenção para o tipo de gráfico que podem ser trabalhados de acordo com a faixa etária dos alunos:

Na construção de um gráfico com crianças maiores a gente trabalha com colunas e barras, mas com crianças menores a gente trabalha com imagens. O principal, são elas entenderem que gráfico é uma representação de uma contagem que eu fiz sobre determinada coisa. (PR, $2^{\circ}$ dia de formação).

Como as autoras Batanero e Diaz (2010) e Kataoka et. al. (2011) afirmam que os conteúdos estatísticos não são evidenciados na formação inicial, os aspectos discutidos anteriormente contribuem para a formação dos licenciandos no que concerne ao tipo de gráfico que deve ser utilizado em cada faixa etária.

Vale destacar as discussões relativas à construção do gráfico da Atividade $03\left(\mathrm{CF}-3^{\circ}\right.$ ano). A discussão teve como ponto principal a proposta de substituição dos quadradinhos utilizados para a construção do gráfico por imagens referentes às festas. A ideia não foi acordada por um licenciando que replicou a sugestão do grupo por não achar conveniente substituir os quadradinhos por imagens. A seguir apresentamos um recorte do diálogo dos licenciandos que instiga a discussão em torno do tema.

[...] Nós vamos dar algumas sugestões. Ao invés de utilizarmos esses quadradinhos, nós utilizaríamos algo que lembrasse as festas. O Círio, nós utilizaríamos o desenho da corda, o Carnaval, poderia ser o trio elétrico, o Natal, o mais clássico, a árvore. (L29, AT03). 
Eu acho que no $3^{\circ}$ ano não se utiliza muito as imagens. Deram como sugestão trocar os quadradinhos pelas imagens. Ai pareceria mais um pouco com o gráfico de pictograma (L23, participando das aulas).

Mas ai que está. [...] A questão de você demonstrar isso [com imagens] é como se nós estivéssemos expondo uma aula sem nada, chamaria menos atenção. A criança quanto mais você chama a atenção para o que você quer ensinar é melhor (L20, AT03).

A discussão mobilizou algumas reflexões no campo da formação concernente a essa atividade. A atividade proposta organizada pelo pesquisador em construir um gráfico de colunas com quadradinhos foi constituir a forma retangular da coluna. No entanto, motivou discussões com sugestões em construir pictogramas com imagens das festas, que na concepção de Kataoka e Hernandez (2010, p. 30) a construção do pictograma poderia ser confeccionado, uma vez que pode ser “[...] construído e usado quando a variável toma poucas categorias e quando o número de observações é pequeno [...]". A mobilização do Saber relacionado à construção de gráficos na atividade do $3^{\circ}$ ano surgiu motivada por situações socializadas em atividades anteriores que fomentaram os questionamentos.

O licenciando chamou a atenção que devido serem alunos do $3^{\circ}$ ano (Figura 2), os conceitos relativos à construção de gráficos poderiam ser aprofundados, saindo do campo das imagens para a construção de colunas. As discussões destacaram a utilização das imagens no processo de ensino e aprendizagem dos alunos e ampliando possibilidades didáticas e pedagógicas para desenvolvimento em sala de aula. Na concepção do licenciando o professor do $3^{\circ}$ ano pode e deve planejar sua atividade relacionada à construção de gráficos utilizando imagens, porque facilita o entendimento contribuindo para a aprendizagem das crianças.

Assim, a partir das discussões evidenciadas na Atividade 03 ( $\mathrm{CF}-3^{\circ}$ ano) no campo formativo os licenciandos pontilharam discussões a respeito do tipo de gráfico que poderia ser construído (gráfico de colunas ou pictogramas), assim, julgamos pertinente o debate ocorrido entre os licenciandos sobre qual gráfico é o mais adequado para ser trabalhado com crianças do $3^{\circ}$ ano, além de que se torna necessário que conheçam os mais variados tipos de gráficos.

Em relação ao Saber relacionado à construção de gráficos voltados as atividades vinculadas ao campo da prática pedagógica os licenciandos mobilizaram esse saber centrado no planejamento das atividades com semelhanças e ampliações no que foi proposto no campo formativo e alicerçado no que preconizam os PCN (Brasil, 1997).

A Atividade $01\left(\mathrm{CP}-3^{\circ}\right.$ ano) desenvolvida no campo da prática pedagógica tinha como objetivo desenvolver uma eleição para líder de turma com isso fazer o levantamento da coleta de dados e construir um gráfico de colunas para a votação do representante de turma. Observe como se deu a dinâmica da atividade desenvolvida pelos licenciandos. 
Vamos agora construir um gráfico para representar a votação que acabamos de realizar. Aqui na mesa tem vários quadradinhos com as cores indicando os candidatos. Vocês vêm aqui, escolhem a cor do quadradinho que se refere ao voto de cada um, viu. É pra escolher a cor do candidato que vocês votaram na urna, tá bom. [...] (L20, AT01).

Os licenciandos desenvolveram de modo semelhante as atividades propostas pelo pesquisador no campo da formação, apresentaram um cartaz com o eixo horizontal para indicar os nomes dos candidatos e o eixo vertical para indicar o número de votos dos candidatos. Ao indicar no eixo horizontal as iniciais dos nomes dos alunos (candidatos) para a construção do gráfico nesta atividade os licenciando apresentaram uma informação nova que não foi anunciada no campo da formação.

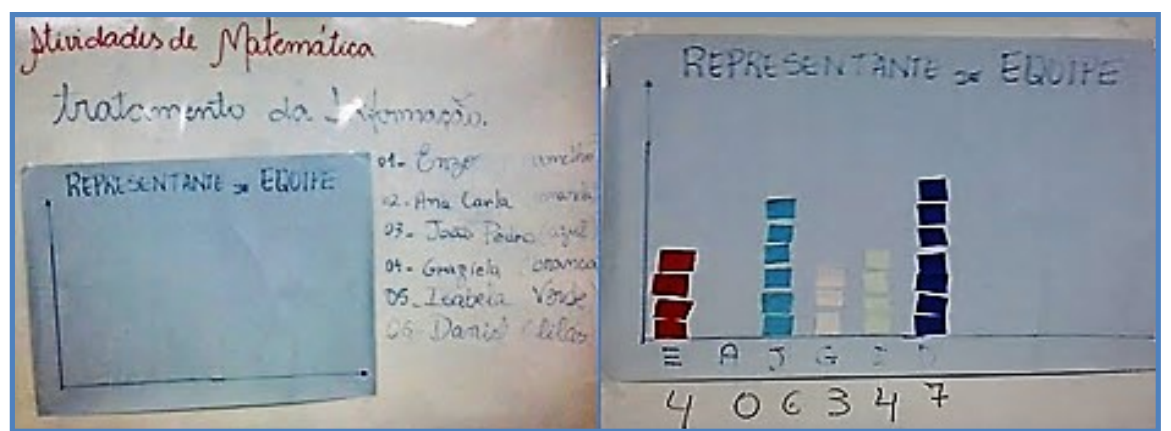

Figura 3: Cartazes antes e depois da construção do gráfico de colunas da eleição do líder de turma / Atividade $01\left(\mathrm{CP}-3^{\circ}\right.$ ano $)$ no campo da prática pedagógica Fonte: $\mathrm{O}$ autor

A construção dos gráficos no campo da prática pedagógica se deu também no mesmo procedimento contemplado no campo da formação. Quanto aos procedimentos para a construção pode-se notar que no campo da formação essa temática foi abordada de um modo geral chamando cada licenciando para colar as figuras das frutas, dos bonequinhos e das festas em determinada categoria apresentada no cartaz (Figura 2). No campo da prática pedagógica os licenciandos confeccionaram quadradinhos de papel referente às cores de cada candidato, chamaram cada aluno para escolher a cor correspondente a cor do candidato e colar no cartaz para construir o gráfico de colunas - semelhantes ao que se fez no campo da formação. Ao final da construção do gráfico realizaram a contagem dos quadradinhos correspondentes aos votos e escritos no eixo horizontal. Podemos evidenciar que os saberes foram mobilizados do campo da formação para o campo da prática pedagógica preservando as mesmas orientações. $\mathrm{O}$ desenvolvimento da atividade suscitou mobilizar saberes relacionado às estratégias didáticas deixando aflorar os saberes pedagógicos da Estatística o qual Shulman (1986) chama de Conhecimento Pedagógico do Conteúdo.

Os licenciandos mobilizaram o Saber relacionado à construção de gráficos a partir dos registros feitos na tabela. Fizeram a votação e a partir da apuração confeccionaram o gráfico. 
No campo da formação foram construídos os gráficos sem a presença desse registro de marcações de votos, entretanto, foi recomendado utilizar dessa estratégia didática como alternativa de motivar os alunos no processo da contagem e a noção de quantidade servindo de auxílio para a sua construção. Guimarães (2009) em seu estudo reforça que o professor dos anos iniciais precisa propor atividades que transponham os dados registrados numa tabela para subsidiar no processo de construção de gráficos.

A atividade $02\left(\mathrm{CP}-3^{\circ}\right.$ ano $)$ foi vivenciada pelos licenciandos no campo da prática pedagógica e organizada em duas equipes o que suscitou a confecção de representações gráficas diferentes (Figura 4) para a mesma atividade, um pictograma de bolinhas e de quadradinhos. Os desdobramentos das atividades estão apresentados nos trechos a seguir.

Grupo 01 - Pictograma de bolinhas

Vamos fazer as bolinhas. Vamos fazer assim, para as bolinhas serem todas iguais, vamos fazer bolinhas azuis. [...] (L24, AT02).

[...]Vamos colocar em Matemática sete bolinhas (L24, AT02).

Tem que colar a bolinha bem nessa direção (apontando para o eixo vertical) (L24, AT02).

Grupo 02 - Pictograma de quadradinhos

Vamos construir um gráfico a partir das informações que acabamos de colher na pesquisa sobre a matéria preferida. Vamos observar as informações contidas naquela tabela ali (tabela feita no quadro) tá bom(L27, AT02).

Que tal fazermos um gráfico de quadradinhos? (L27, AT02).

Então tá aqui a cartolina, lápis, lápis de cor, tinta guache e pincel pra fazerem o gráfico da equipe de vocês (L18, AT02).

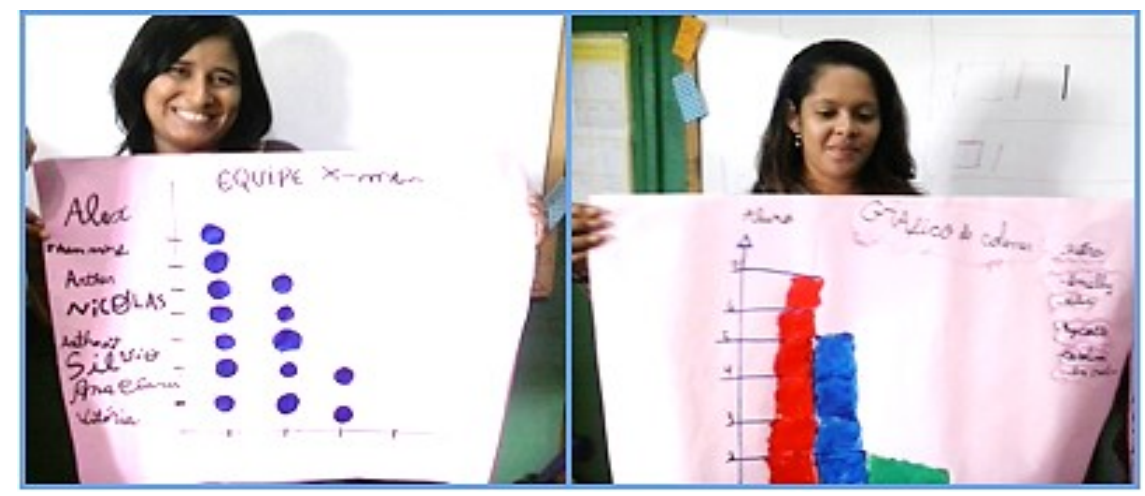

Figura 4: Gráfico Matéria preferida / Atividade $02\left(\mathrm{CP}-3^{\circ}\right.$ ano $)$ grupo 1 e 2, no campo da prática pedagógica Fonte: $\mathrm{O}$ autor

Durante o processo de construção dos gráficos (Figura 4), os licenciandos empreenderam diversos questionamentos - sobre as marcações dos eixos horizontal e vertical que nortearam a colagem das bolinhas e dos quadradinhos e também a quantidade de cada um para cada categoria - as crianças com o intuito de explorar discussões entre elas acerca do Saber relacionado à construção de gráficos no seu processo de formação. Dessa forma, a proposta didática em construir dois tipos diferentes de gráficos mostrou aos licenciandos possibilidades de ampliação de estratégias de ensino que podem ser usadas na forma de representar 
graficamente uma mesma situação na tentativa de contribuir na compreensão dos assuntos. Essa ampliação metodológica anunciada por Shulman (1986) de fazer com que o conteúdo seja compreendido pelos alunos propõe explicar a construção de gráficos com bolinhas e com quadradinhos indicando formas de expressar a votação realizada.

Para a formação dos licenciandos a incursão em atividades pedagógicas nos ambientes escolares tendo-os como protagonistas denota que os Saberes Estatísticos sejam abordados nesse processo alicerçados na prática pedagógica. A abordagem dos Saberes Estatísticos amalgama saberes relacionados, dentre outros, às estratégias metodológicas e ao currículo.

Nessa atividade (Atividade 02, CP - $3^{\circ}$ ano), cabe destacar a inserção da utilização da tabela como forma de organização dos dados coletados e a atenção dada ao processo de cada etapa de construção dos gráficos, explorando análises referentes aos eixos horizontal e vertical, a escala, bem como as relações matemáticas envolvidas nos conceitos estatísticos.

Assim, para a construção do gráfico de bolinhas (Figura 4) os licenciandos interagiram com as crianças durante o processo de confecção das bolinhas, nas explicações dos eixos horizontal (matérias) e vertical (marcações numéricas) e no espaçamento das numerações (escala). Essas explicações conduziram na mobilização da construção do gráfico.

Para a construção do gráfico de quadradinhos (Figura 4) os alunos analisaram as informações da votação presentes na tabela feita na lousa, algo que não foi explicitado no campo formativo, para confeccionar em seguida o gráfico. Reitero que esse processo de transpor os dados da tabela para o gráfico foi evidenciado na Atividade $01\left(\mathrm{CF}-3^{\circ}\right.$ ano) e alicerçado no estudo de Guimarães (2009). A partir dos votos que cada disciplina recebeu deu início a confecção do gráfico. Os alunos desenharam quadradinhos para serem pintados formando uma coluna. Ressaltamos que não foi discutido no campo formativo a construção de gráficos através de pinturas com as crianças, mas que foi um procedimento que sobressaiu na atividade do segundo grupo no campo da prática pedagógica.

Em relação aos Saberes relacionados à construção de gráficos, estes se configuram em um dos saberes de suma importância que compõe os Saberes Estatísticos. Para a construção dos gráficos alguns licenciandos mobilizaram em suas atividades no campo da prática pedagógica. Os tipos de gráficos e os procedimentos de confecção foram explicitados pelos licenciandos durante as atividades com os alunos. Assim, os Saberes Estatísticos concernentes à construção de gráficos apresentaram que se torna necessário a aproximação dos professores propondo atividades contemplando os conteúdos estatísticos para alunos dos anos iniciais. 


\subsection{Saber Relacionado À Leitura E Interpretação Dos Dados}

Evidenciamos também nessas atividades a leitura e interpretação dos dados presentes nos gráficos. Curcio (1987) destaca três modalidades para leitura e interpretação dos dados contidos em gráficos: a leitura dos dados do gráfico, a leitura entre os dados do gráfico e a leitura além dos dados do gráfico. Destaco nestas análises duas delas, a leitura dos dados e a leitura entre os dados. Abaixo, apresento fragmentos das atividades que identificam a comunhão do Saber da leitura e interpretação dos dados nos dois campos de pesquisa.

Primeiramente, destacamos as análises acerca da leitura e interpretação superficial das informações coletadas e organizadas graficamente. Identificamos que em todas as atividades no campo da formação esse saber foi mobilizado destacando a exploração da contagem (voto a voto), a noção de quantidade e a leitura de imagens. De acordo com Guimarães (2009) questionamentos como qual tem mais e qual tem menos são abordados com mais frequência pelos professores em sala de aula e propostos pelos livros didáticos de Matemática para os anos iniciais de escolarização entendendo que para essa faixa etária não seja necessário desenvolver as habilidades interpretativas inserindo as operações matemáticas e, por esse motivo a autora afirma que “[...] questões desse tipo são facilmente compreendidas por crianças já na Educação Infantil" (Guimarães, 2009, p. 98).

Os licenciandos teceram questionamentos referentes à leitura e a interpretação dos dados num estágio inicial de estudo em todas as atividades do campo da formação, como por exemplo: "Quantas crianças quiseram só banana?" (Atividade 01/CF - $1^{\circ}$ ano), "Qual sobremesa que a turma preferiu?"'(Atividade $02 / \mathrm{CF}-2^{\circ}$ ano), "Qual festa ganhou? Quem teve mais voto?" (Atividade 03/CF - $3^{\circ}$ ano). Os licenciandos nas atividades do campo da formação expressaram reflexões relacionadas às habilidades de comparação de quantidades, bem como a utilização de conceitos referentes às habilidades matemáticas de adição, subtração, multiplicação e divisão. Essas habilidades sobressaíram nas atividades no campo escolar (campo da prática pedagógica) buscando compreender as relações matemáticas constituídas na abordagem da leitura entre os dados fundamentada por Curcio (1987).

$\mathrm{Na}$ Atividade $01\left(\mathrm{CF}-1^{\circ}\right.$ ano $)$ torna-se relevante a percepção dos licenciandos quanto as suas análises acerca das informações contidas no gráfico pictograma de frutas, intitulado fruta preferida (Figura 5) construído pelos licenciandos no campo da formação. Observem:

[...] No caso como é $1^{\circ}$ ano, a gente trabalha o método da contagem e ter a noção de quantidade também. Por quê? A criança ainda está aprendendo ideia de quantidade e noção de contar. Quantas crianças quiseram essa fruta aqui? Seria laranja. Aí a gente ia efetuar a contagem,

REVEMAT, Florianópolis (SC), v.14, Edição Especial Educação Estatística, p.1-21, 2019. 
um, dois. Quantas crianças quiseram só a banana? Um, dois, três. Quantas crianças quiseram só a maçã? Um, dois, três. [...] (L26, AT01).

Depois disso, a gente ia perceber quem dai não gosta de fruta. A gente percebeu isso, tem criança que não gosta de comer fruta, faltou uma opção aqui [no gráfico] porque tem criança que não gosta de comer frutas. Também a gente ia perguntar: quantas maçãs têm a mais que uva? Isso a gente ia fazer com o resto, fazer a comparação de um com o outro, E com isso a gente ia explorar o gráfico [...] (L26, AT01).

Nos diálogos apresentados acima, a exploração das informações dos gráficos não ficou vinculada à exposição dos quantitativos referente a cada variável presente nas pesquisas propostas pelas atividades. Os licenciandos nas atividades do campo da formação mobilizaram questionamentos atendendo à faixa etária dos alunos dos anos iniciais não se restringindo a perguntas simples apontando os quantitativos relativos às variáveis (qual tem mais, qual tem menos), mas aprofundando-os com questionamentos que envolviam as operações matemáticas. Destacamos também a percepção dos licenciandos no que diz respeito as opções de frutas sugeridas a inserção da variável "não gosto de frutas" precisava aparecer na pesquisa, devido ao fato de algumas crianças não gostarem de frutas.

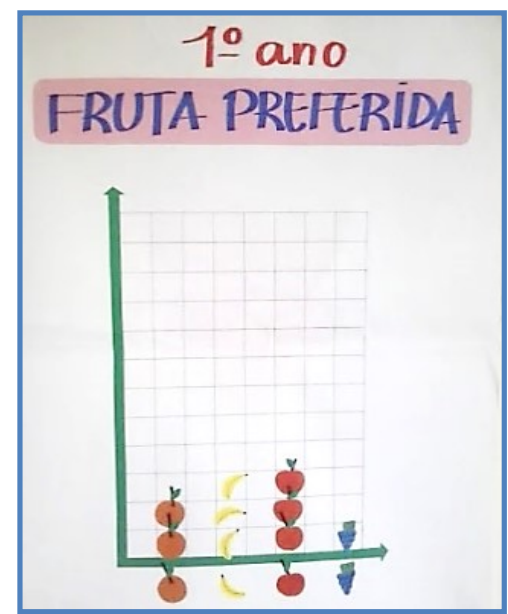

Figura 5: Gráfico "Fruta Preferida" da Atividade $01\left(\mathrm{CF}-1^{\circ}\right.$ ano $)$ / $\left(2^{\circ}\right.$ dia de formação) Fonte: $\mathrm{O}$ autor

Corroborando com os estudos de Curcio (1987) a respeito da leitura e interpretação dos dados, Guimarães (2009) afirma que propor aos alunos fazer comparações entre quantidades somando ou subtraindo não é uma tarefa fácil de resolver, porém, oportuniza aos professores a exploração de conceitos matemáticos no estudo de Estatística.

Os licenciandos do grupo da Atividade $02\left(\mathrm{CF}-2^{\circ}\right.$ ano) fizeram uma interpretação instigante sobre a atividade do $2^{\circ}$ ano no que se refere à interpretação dos dados do gráfico. A atividade previa a votação da sobremesa favorita e foram confeccionados bonecos azuis (meninos) e rosas (meninas), nesse sentido, o gráfico construído foi um pictograma em barras com bonecos (Figura 6) que conduziram a questionamentos analisando os dados de cada variável dentro da perspectiva do quantitativo do número de meninos e do número de meninas 
que escolheram determinada sobremesa. Os fragmentos a seguir anunciam como se deu os desdobramentos da atividade.

No sorvete a quantidade [de pessoas] seria misturado tanto meninos, tanto de meninas, total 8 pessoas. Já a pergunta que a gente fez seria: quantas meninas escolheram a opção sorvete? Seis! De oito, seis meninas escolheram sorvete. No caso do doce, quantos meninos escolheram doce? Três! Então, de dez, três meninos escolheram doce (L24, AT02).

Qual a sobremesa que a turma preferiu? (L10, AT02)

L10 2: O doce foi mais meninos ou mais meninas?

Licenciandos: Meninas!

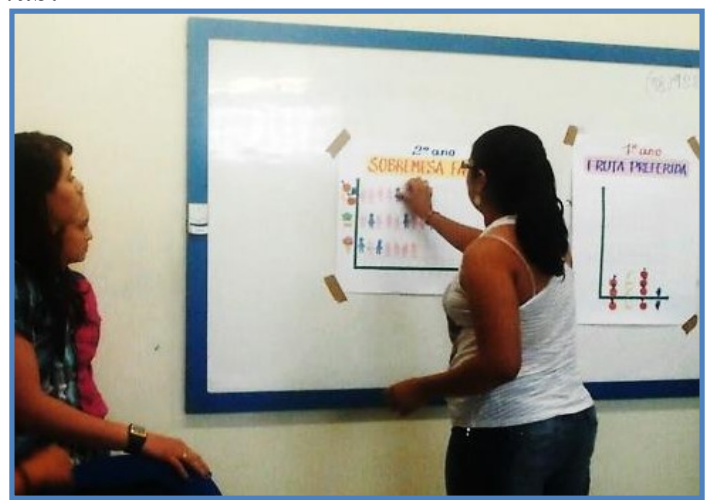

Figura 6: Gráfico "Sobremesa Favorita" da Atividade $02\left(\mathrm{CF}-2^{\circ}\right.$ ano $) /\left(2^{\circ}\right.$ dia de formação $)$ Fonte: $\mathrm{O}$ autor

Nessa atividade (Atividade 02, $\mathrm{CF}-2^{\circ}$ ano) no campo da formação, os licenciandos destacaram as quantidades de votos definidos para meninos e meninas nas opções sorvete e doce. Perguntaram: "Qual a sobremesa que a turma preferiu?" (L10, AT02) e "O doce foram mais meninos ou meninas?". Nota-se que as atividades propostas aos licenciandos sugerem interpretações singulares e subjetivas no sentido de que diante de informações presentes no gráfico podem ser apresentadas múltiplas maneiras de exploração dos dados. Com um recurso que propõe bonecos diferenciados para os gêneros a interpretação dos dados foi direcionada às quantidades referente ao sexo. Assim, pode-se perceber que o Saber relacionado à leitura e interpretação dos dados evidenciou na Atividade $02\left(\mathrm{CF}-2^{\circ}\right.$ ano $)$ apenas a leitura direta dos dados, limitadas às comparações entre os quantitativos de meninos e meninas dentro da mesma variável.

Segundo as concepções do pesquisador e da professora para atividades voltadas ao $1^{\circ} \mathrm{e}$ $2^{\circ}$ anos os licenciandos precisavam utilizar valores pequenos nas atividades, enquanto que para os alunos do $3^{\circ}$ as atividades podem explorar valores maiores

No campo da prática pedagógica os Saberes relacionado à leitura e interpretação dos dados no que diz respeito à leitura superficial dos dados contidos nos gráficos foram engendrados em todas as atividades. Também foi evidenciada nesse campo a leitura dos dados que abordam habilidades matemáticas. 
Os licenciandos exploraram os dados contidos no gráfico de colunas da eleição do líder de turma na Atividade $01\left(\mathrm{CP}-3^{\circ}\right.$ ano) ministrada aos alunos do $3^{\circ}$ ano no campo da prática pedagógica. Nesta atividade, o Saber relacionado à leitura e interpretação dos dados mobilizado no campo da formação sobressaiu na formação dos licenciandos durante a prática docente, exploraram intensamente as habilidades de leitura e interpretação dos dados no desenvolvimento da atividade, não ficaram limitados somente à leitura dos dados.

Nessa atividade (Atividade 01, $\mathrm{CP}-3^{\circ}$ ano) os licenciandos deram ênfase a leitura e interpretação dos dados presentes nos gráficos construídos pelos alunos. A análise dos dados mobilizados pelos licenciandos conduziram interpretações que promoveram explorar diversos questionamentos (qual tem mais, qual tem menos, quantos têm a mais, quantos têm a menos), dentro de uma atividade matemática acerca do conteúdo de Estatística para os anos iniciais do Ensino Fundamental. Apresentamos um recorte dos diálogos como discorreu a aula fazendo referência a esse objeto de estudo (Figura 3).

L13: Quanto é a soma dos votos do E...(aluno da equipe vermelha, 4 votos) com a G...(aluna da equipe branca, 3 votos) e com a I...(aluna da equipe verde, 4 votos)?

Alunos: 11 !

L29: Prestem atenção. Faltam quantos votos para a G...(aluna da equipe branca) ganhar?

L20: Faltam quantos votos? [...]

Aluno: 3!

L29: Faltam quantos votos para ela ganhar?

Alunos: 5 !

Nesse sentido, os questionamentos feitos pelos licenciandos segundo a concepção de Curcio (1987) foram numa perspectiva na leitura dos dados e na leitura entre os dados, foi constatado que a atividade contribuiu na formação dos alunos e para a formação dos licenciandos promovendo o desenvolvimento das habilidades básicas de leitura e interpretação de dados estatísticos presentes em gráficos e tabelas.

Os licenciandos conduziram na esfera do campo da prática pedagógica questionamentos relacionados às habilidades das operações matemáticas, sobretudo, no que concerne à adição e subtração, bem como comparações no sentido de demonstrar igualdade entre variáveis. A ideia do voto em branco indagado por uma aluna motivou os licenciandos a tecerem explicações acerca desse questionamento. O mesmo não precisa ser registrado no gráfico, caso for não representará o número de alunos da sala. Isso foi transcorrido na Atividade $02\left(\mathrm{CP}-3^{\circ}\right.$ ano) como podemos observar no diálogo abaixo (Figura 4).

\section{Pictogramas de Bolinhas}

L24: Tem [voto] branco também né. A gente pode votar em branco né. Vocês não votaram em nenhuma matéria. Todo mundo que tá aqui gosta de alguma dessas matérias.

Aluna: Eu gosto dessa (Matemática).

Aluno: Tá aqui em branco tia, olha! 
L24: Pois é, mas se você colocar [uma bolinha] no branco bem aqui ele vai aparecer que número aqui?

Alunos: Um!

L24: Teve algum voto?

Alunos: Não!

L24: Então, não pode colocar.

Aluna: Senão vai ter quinze né tia.

O contexto de formação dos licenciandos quanto à mobilização dos Saberes de Conteúdo Estatístico do campo da formação para o campo da prática pedagógica potencializou, de modo particular, a leitura e a interpretação dos dados em todas as atividades desenvolvidas, sendo assim, demonstrou que o conteúdo específico da Estatística gerou e movimentou ações no ambiente profissional do professor caracterizando, dessa forma, a importância desses saberes para a prática docente.

\section{Considerações Finais}

Os assuntos estatísticos elencados nos Saberes Estatísticos - saber relacionado à construção de gráficos e o saber da leitura e interpretação dos dados - foram discutidos no campo da formação com a participação intensa dos licenciandos nos debates, sob duas abordagens. A primeira se deu dentro de uma perspectiva formativa que abordou o conteúdo de Estatística sem conexão com o trabalho docente. A segunda abordagem foi vinculada à prática profissional dos professores. A partir de atividades potencialmente didáticas e pedagógicas relacionadas ao tratamento da Estatística nos anos iniciais, os licenciandos se aproximaram de situações de aprendizagens associadas à realidade do cotidiano escolar.

No tocante ao Saber relacionado à construção de gráficos foi explicitado no campo da formação e no campo da prática pedagógica com semelhanças e diferenças. Em algumas atividades os licenciandos abordaram da mesma forma como foi realizado no campo formativo, porém, em outras, ampliaram a dinâmica de construção de gráfico com os alunos que contribuíram para sua formação, pois ao ampliar os conceitos e formas de construir um gráfico, os licenciandos estão agregando à sua formação múltiplas possibilidades de desenvolver esses saberes no exercício da sua prática docente.

No saber da leitura e interpretação dos dados a ênfase está no momento da exploração dos dados, fazer com que os alunos entendam os dados contidos nas diversas representações gráficas na forma de gráficos de colunas, de pictogramas e em gráficos de setores. No campo da formação, a leitura dos dados ganhou destaque no primeiro dia de formação com intensas 
discussões sobre a exploração da leitura dos dados, conduzidos pelo pesquisador e pela professora. Já no segundo dia a formação foi instigada pela exploração da leitura e interpretação, tendo como atores do processo os próprios licenciandos. Assim, os questionamentos pertinentes à leitura e à interpretação dos dados reverberaram em suas atividades no campo da prática pedagógica.

Concluímos que os Saberes Estatísticos, quando abordados nos anos iniciais do Ensino Fundamental, devem repercutir na prática pedagógica dos professores através de atividades envolvendo investigações estatísticas que promovam o desenvolvimento do senso crítico das crianças e em atividades que levem os alunos a vivenciarem a coleta de dados em situações reais, desenvolvendo neles a capacidade de argumentar, dar sua opinião, analisar o processo de construção das representações gráficas e compreensão das informações organizadas através de gráficos ou tabelas.

\section{Referências}

Batanero, C., \& Diaz, C. (2010). Training teachers to teach statistics: What can we learn from research? Statistique et Enseignement, 1 (10), 5-20.

Brasil (1997). Ministério da Educação. Parâmetros Curriculares Nacionais: Matemática. Brasília.

Brasil (2018). Ministério da Educação. Base Nacional Curricular Comum. Brasília. Disponível em http://basenacionalcomum.mec.gov.br/

Carzorla, I. M. (2002). A relação entre a habilidade viso-pictória e o domínio de conceitos estatísticos na leitura de gráficos. Tese (Doutorado em Educação). Faculdade de Educação, Universidade Estadual de Campinas. Campinas, SP.

Carzorla, I. M. (2004). Educação estatística aplicada à educação Salvador: Faculdade Jorge Amado.

Cazorla, I. M.(2015). O Ensino de Estatística no Brasil. Brasília: Sociedade Brasileira de Educação Matemática. Recuperado de http://www.sbem.com.br/gt 12/arquivos/cazorla.htm.

Curcio, F. R. (1987). Comprehension of mathematical relationship expressed in graphs. Journal for Research in Mathematics, 18 (5), 382-393.

Guimarães, G (2009). Refletindo sobre a Educação Estatística na sala de aula. In: G. Guimarães, \& R. Borba. (Eds). Reflexões sobre o Ensino de Matemática nos anos iniciais de escolarização. Recife: SBEM. 
Kataoka, V. Y. et al. (2011). A educação estatística no ensino fundamental II em Lavras, Minas Gerais, Brasil: avaliação e intervenção. Revista Latinoamericana de Investigación en Matemática Educativa, México, 14 (2), 233-263.

Kataoka, V. Y., \& Hernandez, H (2010). Perfil da turma. In: I.M. Cazorla, \& R. Santana (Eds.). Do Tratamento da Informação ao Letramento Estatístico. Itabuna: Via Litterarum.

Lopes, C. E. (1998). A probabilidade no ensino fundamental: uma análise curricular. Dissertação (Mestrado em Educação). Faculdade de Educação, Universidade Estadual de Campinas. São Paulo.

Lopes, C. E. (2003). O conhecimento Profissional dos Professores e suas relações com Estatística e Probabilidade na Educação Infantil. Tese (Doutorado em Educação). Universidade Estadual de Campinas, São Paulo, Brasil.

Lopes, C. E. (2010). Os desafios para educação estatística no Currículo de Matemática. In: C.E. Lopes et. Al (Eds). Estudos e reflexões em educação estatística. Campinas, SP: Mercado de Letras.

Lopes, C. E. (2008). O ensino da Estatística e da Probabilidade na Educação Básica e a Formação dos Professores. Caderno Cedes, Campinas, 28 (74), 57-73.

Manfredo, E. C. G., Gonçalves,T.O., \& Levy, L. F (2011). Formação estatística de professores que ensinam Matemática nos anos iniciais da Educação Básica. In Anais da $8^{a}$ Conferência Interamericana de Educação Matemática, Recife, Pernambuco.

Martins, M. N. P, Carvalho, C. F. de (2018). O ensino de gráficos estatísticos nos anos iniciais. Revista de Ensino de Ciências e Matemática, 9 (2), 247-264.

Souza, L. de O. (2014). O desenvolvimento profissional de professores para o ensino de probabilidade em tarefas de investigação estatística. In: C.E. Lopes (Eds). Os Movimentos da Educação Estatística na Escola Básica e no Ensino Superior. Campinas, SP: Mercado de Letras. 